\title{
Management of patients during and after exacerbations of chronic obstructive pulmonary disease: the role of primary care physicians
}

This article was published in the following Dove Press journal:

International Journal of General Medicine

I3 September 201 I

Number of times this article has been viewed

\author{
Barbara P Yawn' \\ Byron Thomashow ${ }^{2}$ \\ 'Department of Research, Olmsted \\ Medical Center, Rochester, MN, \\ USA; ${ }^{2}$ Division of Pulmonary, \\ Allergy, Critical Care, Department \\ of Medicine, Columbia University, \\ College of Physicians and Surgeons, \\ New York, NY, USA
}

\begin{abstract}
Current treatments have failed to stem the continuing rise in health care resource use and fatalities associated with exacerbations of chronic obstructive pulmonary disease (COPD). Reduction of severity and prevention of new exacerbations are therefore important in disease management, especially for patients with frequent exacerbations. Acute exacerbation treatment includes short-acting bronchodilators, systemic corticosteroids, and antibiotics if bacterial infections are present. Oxygen and/or ventilatory support may be necessary for life-threatening conditions. Rising health care costs have provided added impetus to find novel therapeutic approaches in the primary care setting to prevent and rapidly treat exacerbations before hospitalization is required. Proactive interventions may include risk reduction measures (eg, smoking cessation and vaccinations) to reduce triggers and supplemental pulmonary rehabilitation to prevent or delay exacerbation recurrence. Long-term treatment strategies should include individualized management, addressing coexisting nonpulmonary conditions, and the use of maintenance pharmacotherapies, eg, long-acting bronchodilators as monotherapy or in combination with inhaled corticosteroids to reduce exacerbations. Self-management plans that help patients recognize their symptoms and promptly access treatments have the potential to prevent exacerbations from reaching the stage that requires hospitalization.
\end{abstract}

Keywords: COPD, beta-agonists, anticholinergics, self-management plan

\section{Introduction}

Exacerbations of chronic obstructive pulmonary disease (COPD) manifest as aggravated respiratory symptoms that can negatively impact a patient's disease trajectory, often with grim consequences to the individual and society. The Global Initiative for Chronic Obstructive Lung Disease (GOLD) defines exacerbations as "an event in the natural course of the disease characterized by a change in the patient's baseline dyspnea, cough, and/or sputum that is beyond normal day-to-day variations, is acute in onset, and may warrant a change in regular medication." Variations in defining, reporting, or diagnosing episodes may mask the true health and economic burden of exacerbations. Nevertheless, exacerbations are expected to increase in tandem, with projections that deaths from underlying COPD will rise by more than $30 \%$ over the next decade without interventions to cut risks. ${ }^{2}$ Compounding the societal health impact are the staggering costs involved in treating acute exacerbations, especially if they are severe in nature and therefore warrant hospitalization. The total cost of caring for COPD in the United States is rapidly approaching US $\$ 50$ billion per year. Most estimates suggest that $70 \%$ of that cost relates to treating exacerbations, particularly severe episodes requiring hospitalization and often intensive care. ${ }^{3}$
Correspondence: Barbara PYawn Department of Research, Olmsted Medical Center, 210 Ninth Street SE, Rochester, MN 55904, USA

Tel +l 5072872758

Fax + I 5072872722

Email byawn@olmmed.org 
Exacerbation-prone individuals may be negatively affected in terms of a decreased quality of life, increased hospitalization, and premature deaths, either as a consequence of COPD or coexisting diseases. ${ }^{4}$ Exacerbation frequencies and associated hospitalizations in those who are prone to exacerbations typically range from 0.5 to 5.2 exacerbations (depending on definitions used) and from 0.09 to 2.40 hospitalizations per year, respectively. ${ }^{5-7}$ Patients with severe COPD who have frequent exacerbations $(\leq 6$-month intervals; $>$ three per year) have a more rapid decline in lung function and worse health-related quality of life than those who experience infrequent exacerbations. ${ }^{8}$ However, data from the Evaluation of COPD Longitudinally to Identify Predictive Surrogate Endpoints (ECLIPSE) initiative suggest that there is a frequent-exacerbation phenotype that is independent of disease severity. ${ }^{9}$ Exacerbation duration is variable but may last up to 5 weeks, ${ }^{10}$ and the impact can be prolonged or permanent; ${ }^{11}$ there is also a high risk of a recurring exacerbation in the 8-week period following an index event. ${ }^{12}$ The devastating consequences of exacerbations are underscored by high rates of relapse ( $22 \%-32 \%$ of emergency department patients visit the department again), ${ }^{13} 1$-year (25\%) and 5-year (44\%) hospital readmissions, ${ }^{14}$ and overall treatment failures $(32 \%){ }^{15}$ as well as high exacerbationrelated fatalities $(2.5 \%-10.0 \%)$, increasing in intensive care unit patients to $20 \%-24 \% .{ }^{16,17}$

Reports are beginning to illuminate the gap between guideline-recommended and actual treatment and follow-up care of hospitalized COPD patients. One retrospective analysis of these patients showed that prescribed respiratory drugs were underused, overused, or misused. ${ }^{18}$ A separate retrospective cohort study showed that hospitalized patients with acute exacerbations received adequate care, but that there were opportunities to improve treatment in both the inpatient and outpatient settings. ${ }^{19}$ Recognition of the cost-prohibitive nature and frequent treatment of recurrent exacerbations in hospitals has added to the interest in treating milder or frequent episodes in the primary care setting. Ultimately we will need to balance the cost of potential preventive therapies versus the benefit of preventing exacerbations. The aim of this review is to describe strategies that may improve the prevention and treatment of exacerbations.

\section{Triggers and effects of COPD exacerbations}

The transition from stable-state COPD to onset of an exacerbation typically involves amplified airway inflammation. ${ }^{1}$ Infections of the tracheobronchial tree (viral and bacterial), exposure to air pollution (eg, inhalation of tobacco smoke, occupational and environmental exposure to particulates or noxious gases), and suboptimal treatment adherence account for most identifiable causes of exacerbations. ${ }^{1}$ Exacerbations triggered by respiratory viral mono- or coinfections are more likely to be severe, prolonged, and associated with hospital admissions compared with episodes where respiratory viruses were not detected. Further investigation is needed to establish whether chronic respiratory viral infection of stable COPD patients' airways predisposes patients to exacerbations. ${ }^{20}$ Many exacerbations are triggered by a bacterial infection caused by, for example, Streptococcus pneumoniae, Haemophilus influenzae, Moraxella catarrhalis, and Pseudomonas aeruginosa. ${ }^{20}$ Elevated levels of the latter pathogen are more likely to be associated with severe COPD or when systemic steroids and/ or antibiotics had been prescribed in the preceding months. ${ }^{21}$ In addition, Bordetella pertussis, the re-emergent pathogen responsible for pertussis (whooping cough), has been associated with $31 \%$ of acute exacerbations of chronic bronchitis, according to one pilot study. ${ }^{22}$ While infections are the most common cause of exacerbations, ${ }^{1}$ the apparent increased susceptibility to this etiologic factor in patients with COPD is not well understood. Recent evidence suggests that an altered airway epithelial cell phenotype may contribute to increased susceptibility to viral infection in patients with COPD compared with control subjects. ${ }^{23}$

Exacerbations may also increase the risk of nonpulmonary events and related mortality. Specific molecular pathways culminating in exacerbations remain to be elucidated, but elevated systemic inflammatory markers are often present during acute exacerbations and have been associated with a small but statistically significant risk of stroke and cardiovascular events. ${ }^{24}$ Worsening bronchoconstriction from an exacerbation may elevate pulmonary artery pressures, placing an increased burden on the right side of the heart. ${ }^{24} \mathrm{~A}$ higher post-exacerbation myocardial infarction incidence has been reported in patients with more frequent exacerbations, although the reasons for this finding remain unclear. ${ }^{24}$ The recent ECLIPSE study showed that more frequent exacerbations were also associated with greater impairment in health status. ${ }^{9}$

Patients who have frequent exacerbations have been defined as having more than the annual median number of episodes for a given study, usually two steroid- and/or antibiotic-requiring or three symptom-defined exacerbations. ${ }^{20}$ These patients can exhibit elevations in specific blood and airway-derived biomarkers compared with those who have infrequent exacerbations, ${ }^{25,26}$ generally have a faster decline 
in functional status, ${ }^{27}$ are more prone to rehospitalization, ${ }^{14}$ and are more likely to be housebound ${ }^{20}$ than those who have infrequent exacerbations. Patients hospitalized with COPD exacerbations are also more likely to have coexisting pneumonia and diabetes than hospitalized patients without COPD. ${ }^{28}$

\section{Diagnosis of an exacerbation}

Diagnosis and staging of COPD exacerbations depend on symptom-based criteria and/or health care resource utilization (Table 1). Since increasing confusion may be part of respiratory compromise, it may also be beneficial to assess a patient's mental status during evaluation (Table 2). Of the known hospitalization indicators, escalating respiratory distress, onset of respiratory acidosis, significant nonpulmonary conditions, and the need for ventilatory (invasive or noninvasive mechanical) support are especially important, since they are associated with an increased risk of death. ${ }^{1}$

While a severe exacerbation is almost always identified and treatment provided, many milder events go unreported by patients ${ }^{29}$ or are labeled by clinicians as upper respiratory tract infections or acute bronchitis. Recognizing and appropriately treating all exacerbations, including milder symptom worsening reported by patients, may help prevent future exacerbations. Composite indices can help identify patients at increased risk of developing a future exacerbation. Examples include indices for (1) BODE (body mass index, airflow obstruction [forced expiratory volume in 1 second $\left.\left(\mathrm{FEV}_{1}\right)\right]$, dyspnea, and exercise capacity $)^{30}$ and (2) DOSE (dyspnea scale, airflow obstruction $\left[\mathrm{FEV}_{1}\right]$, smoking status [current versus former], and prior exacerbation frequency). ${ }^{31}$ In addition, the Exacerbations of Chronic Pulmonary Disease Tool, a Patient-Reported Outcome measure initiative, has

Table I Commonly used definitions of exacerbation severity ${ }^{33,34}$

\begin{tabular}{ll}
$\begin{array}{l}\text { Exacerbation symptoms } \\
\text { - Increase in dyspnea } \\
\text { - Change in sputum volume } \\
\text { - Change in sputum purulence }\end{array}$ \\
\hline $\begin{array}{l}\text { Degree of exacerbation } \\
\text { (number of symptoms }{ }^{\mathrm{a}} \text { ) }\end{array}$ & Feature \\
\hline Mild (I of 3 present) & $\begin{array}{l}\text { Symptoms } s^{\mathrm{b}} \text { can be controlled by } \\
\text { increasing prescribed medication dose }\end{array}$ \\
Moderate (2 of 3 present) & $\begin{array}{l}\text { Symptoms }{ }^{\mathrm{b}} \text { require corticosteroids } \\
\text { and/or antibiotics } \\
\text { Symptoms need evaluation in a } \\
\text { hospital/ED/intensive care unit }\end{array}$ \\
\hline
\end{tabular}

Notes: a Beyond periodic variability necessitating a change in medical management; ${ }^{b}$ Treatment in a primary care setting is sufficient for patients with few comorbidities. Abbreviation: ED, emergency department. been designed to standardize evaluations of the frequency, severity, and duration of acute exacerbations of COPD and chronic bronchitis. A recent observational study suggests that this 14-item digital diary is reliable, valid, and sensitive to change with exacerbation recovery. ${ }^{32}$

Since no single test can fulfill all requirements, additional evaluations are needed to accurately identify exacerbationprone patients. Inadequate recording of relevant factors (medical history, risk factors, exercise tolerance), lack of equipment, clinicians with limited training, as well as patients with multiple chronic conditions may further complicate diagnosis.

Investigational biomarkers associated with exacerbation etiology, severity, and recovery can potentially augment the current diagnostic toolkit. One example is the hormone precursor procalcitonin, which is elevated in serum when bacterial infections are present. ${ }^{33}$ Ongoing studies are needed to assess the routine use of procalcitonin to diagnose these exacerbations (in order to reduce patient exposure to antibiotics); its use has not yet been recommended by guidelines. Further studies are also needed to assess the value of routine testing for biomarkers found in association with exacerbations, such as fractional exhaled nitric oxide and C-reactive protein (CRP). ${ }^{33-35}$

\section{Treatment of acute exacerbations}

Given the frequently fatal nature of COPD exacerbations, they must be recognized early and accurately to allow prompt initiation of therapy. Early detection and treatment of exacerbations can improve patients' wellbeing and health-related quality of life and reduce hospitalizations. ${ }^{1}$ The recommended treatment algorithm for exacerbations is delineated in Figure 1. 1,36,37 Pharmacotherapy is intended to relieve dyspnea, reduce airway inflammation, improve lung function, and eradicate infections, potentially moderating disease progression. A reliable predictor of a recurrent exacerbation is a history of previous exacerbations. ${ }^{6,9}$

\section{Bronchodilators}

The first step in the treatment of an exacerbation is to increase the dose of inhaled bronchodilator to decrease dyspnea. ${ }^{1}$ Short-acting $\beta$-agonists (SABAs) are used as needed because they have a rapid onset of action on bronchoconstriction. Prescriptions of these bronchodilators are subject to consideration of known adverse events for SABAs (eg, hypokalemia). ${ }^{1}$ Combining SABAs with inhaled short-acting anticholinergics (SAACs) may have additional benefit. Common side effects of anticholinergics include dry mouth and 
Table 2 Hospitalization indicators and evaluations of exacerbations ${ }^{\prime}$

\section{General indications for hospitalization}

- Frequent episodes

- Diagnostic uncertainty

- Advanced age

- Change in mental status

- Symptoms that are poorly responsive to current treatment

- Advanced COPDa

- Little or no psychosocial support

- Intensive care is warranted for life-threatening episodes associated with: respiratory failure; shock; hemodynamic instability; hypoxic renal, hepatic, or brain dysfunction

\section{Symptomatic indications and diagnostic tests}

\begin{tabular}{ll}
\hline Indication $^{\text {b }}$ & Diagnostic test \\
\hline $\begin{array}{l}\text { - Exposure to risk factors (genetic predisposition; inhalation of tobacco } \\
\text { smoke or environmental pollutants) and/or low exercise tolerance }\end{array}$ & $\begin{array}{l}\text { Accurate recording of medical history and risk factors, preferably } \\
\text { aided by validated questionnaires, can identify undiagnosed } \\
\text { COPD cases }\end{array}$ \\
$\begin{array}{ll}\text { - Intensified respiratory symptoms (cough, sputum production, } & \text { - Baseline spirometry (FEV,/FVC) is useful to confirm COPD, but } \\
\text { and dyspnea) } & \text { is not indicated for patients during an episode } \\
& \text { of severe episodes }\end{array}$
\end{tabular}

- Change in sputum volume and appearance

- Lethargy, fever, fatigue

- Elevation of jugular venous pressure and pitting ankle edema

- Signs of respiratory failure

- $\mathrm{SaO}_{2}<92 \%$

- Chest discomfort
- Confirm presence of bacterial infections with sputum culture or molecular typing

- Confirm suspected right heart failure with radiography

- Quantify hypercarbia or hypoxemia with ABG testing

If unresponsive or poorly responsive to conventional exacerbation treatment:

- Identify non-COPD (eg, cardiac arrhythmia, ischemia) causes of dyspnea with radiography, cardiac enzyme

(for suspected ischemia), and brain natriuretic peptide

(for CHF) measurements

- Consider nonadherence to prescribed treatment

- Laboratory tests for alterations in glycemia, acid-base balance, electrolytes

- Hematocrit $>55 \%$ associated with polycythemia and arterial hypoxemia (usually seen in current smokers)

- Low hematocrit indicative of poor prognosis in patients with severe COPD receiving long-term oxygen treatment; consider complications such as pulmonary embolism or edema

Notes: ${ }^{\mathrm{FFEV}} / \mathrm{FVC}<70 \%$; $\mathrm{FEV}_{1}<50 \%$ with respiratory symptoms either at rest or upon minimal exertion; 'bndications with or without a prior COPD diagnosis may warrant several evaluations. There could potentially be a reciprocal and causal relationship between COPD and nonpulmonary conditions. Examples of the latter conditions include cardiovascular diseases, stroke, pneumonia, sepsis, diabetes mellitus, and renal or hepatic failure; ${ }^{\mathrm{c}} \mathrm{PaO}_{2}<8.0 \mathrm{kPa}$ with or without $\mathrm{PaCO}$.

Abbreviations: ABG, arterial blood gas; CHF, congestive heart failure; COPD, chronic obstructive pulmonary disease; FEV forced vital capacity; Pa, partial pressure; Sa, saturation. 


\section{One or more symptoms}

- Increase in dyspnea, change in sputum volume, change in sputum purulence; oxygen or ventilatory support at any stage in presence of new or established respiratory failure

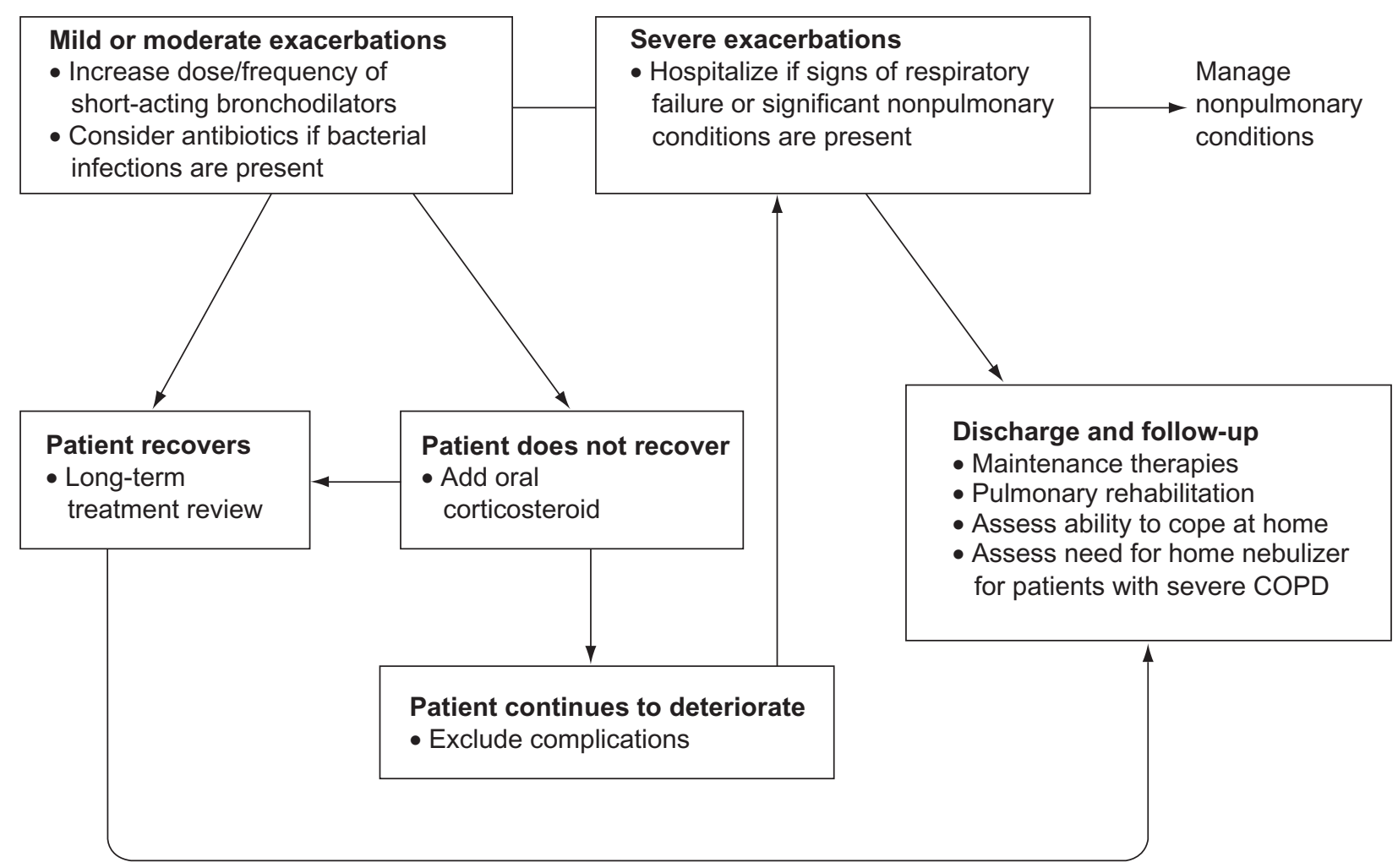

Figure I Treatment algorithm for patients with exacerbations.

Adapted from the Global Initiative for Chronic Obstructive Lung Disease guidelines, ${ }^{1}$ Anthonisen et al, ${ }^{36}$ and Celli et al. ${ }^{37}$

Abbreviation: COPD, chronic obstructive pulmonary disease.

constipation..$^{38}$ If patients are already receiving maintenance pharmacotherapies, some caution needs to be exercised when adding regular doses of SABAs or SAACs, since side effects could increase. Methylxanthine derivatives may play a role as second-line therapies in selected cases where patients are poorly responsive to SABAs or SAACs $;{ }^{1}$ however, their significant potential side effects when used in high doses or combined with other common chronic disease therapies warrant close clinical and biochemical monitoring for possible adverse events.

\section{Corticosteroids}

The major use for systemic steroids is in combination with other therapies, eg, bronchodilators, during an acute exacerbation. ${ }^{1}$ No steroid taper is required for a short course of systemic steroid therapy, per GOLD guidelines. ${ }^{1}$ Recent data suggest that oral corticosteroids are as effective as intravenous corticosteroids in patients hospitalized with exacerbations; however, prolonged treatment with oral corticosteroids ( $>10$ days) does not result in greater efficacy and increases the risk of side effects such as hyperglycemia and muscle atrophy. ${ }^{1}$ While an approved inhaled corticosteroid (ICS)/longacting $\beta$-agonist (LABA) combination is used in the context of preventing the next exacerbation, the GOLD guidelines state that the ICS, budesonide, "alone, or in combination with formoterol may be an alternative (although more expensive) to oral glucocorticosteroids in the treatment of exacerbations."

\section{Antibiotics}

Bacterially triggered exacerbations are usually amenable to appropriate antibiotic therapy. ${ }^{1}$ Current antibiotic recommendations (Table 3) will depend on the bacterial strains that are responsive or resistant to antimicrobial therapies. Relevant factors that may guide specific antibiotic choices are drug 
Table 3 Antibiotic treatment in exacerbation of COPD

\begin{tabular}{|c|c|c|c|}
\hline $\begin{array}{l}\text { COPD exacerbation } \\
\text { indication }^{\mathrm{a}, \mathrm{b}}\end{array}$ & Oral treatment ${ }^{c}$ & $\begin{array}{l}\text { Alternative oral } \\
\text { treatment }^{c}\end{array}$ & Parenteral treatment ${ }^{c}$ \\
\hline $\begin{array}{l}\text { Group A } \\
\text { (mild exacerbation: no risk } \\
\text { factors for poor outcome) }\end{array}$ & $\begin{array}{l}\text { Patients with only one cardinal } \\
\text { symptom }{ }^{d} \text { should not receive antibiotics } \\
\text { If indication then: } \\
\text { - } \beta \text {-lactam (penicillin, ampicillin/ } \\
\text { amoxicillin }{ }^{\mathrm{e}} \text { ) } \\
\text { - Tetracycline } \\
\text { - Trimethoprim/sulfamethoxazole }\end{array}$ & $\begin{array}{l}\text { - } \beta \text {-lactam/ } \beta \text {-lactamase } \\
\text { inhibitor (co-amoxiclav) } \\
\text { - Macrolides (azithromycin, } \\
\text { clarithromycin, } \\
\text { roxithromycin }{ }^{f} \\
\text { - Cephalosporins - second } \\
\text { or third generation } \\
\text { - Ketolides (telithromycin) }\end{array}$ & \\
\hline $\begin{array}{l}\text { Group B } \\
\text { (moderate exacerbation } \\
\text { with risk factor(s) for poor } \\
\text { outcome) }\end{array}$ & $\begin{array}{l}\text { - } \beta \text {-lactam/ } \beta \text {-lactamase inhibitor } \\
\text { (co-amoxiclav) }\end{array}$ & $\begin{array}{l}\text { - } \text { Fluoroquinolones }^{f} \\
\text { (gemifloxacin, levofloxacin, } \\
\text { moxifloxacin) }\end{array}$ & $\begin{array}{l}\text { - } \beta \text {-lactam/ } \beta \text {-lactamase } \\
\text { inhibitor (co-amoxiclav, } \\
\text { ampicillin/sulbactam) } \\
\text { - Cephalosporins (second } \\
\text { or third generation) } \\
\text { - Fluoroquinolones }{ }^{f} \\
\text { (levofloxacin, moxifloxacin) }\end{array}$ \\
\hline $\begin{array}{l}\text { Group C } \\
\text { (severe exacerbation with risk } \\
\text { factors for Pseudomonas } \\
\text { aeruginosa infection) }\end{array}$ & $\begin{array}{l}\text { In patients at risk for Pseudomonas } \\
\text { infections: } \\
\text { - Fluoroquinolones }{ }^{f}(\text { ciprofloxacin, } \\
\left.\text { levofloxacin - high } \text { dose }^{g}\right)\end{array}$ & & $\begin{array}{l}\text { - } \text { Fluoroquinolones }^{f} \\
\text { (ciprofloxacin, levofloxacin } \\
\text { - high dose }{ }^{g} \text { ) } \\
\text { - } \beta \text {-lactam with } P \text {. aeruginosa activity }\end{array}$ \\
\hline
\end{tabular}

Notes: Relevant risk factors: presence of comorbid diseases, severe COPD, frequent exacerbations ( $>3 / y e a r)$, and antimicrobial use in the last 3 months. ${ }^{a}$ All patients with symptoms of a COPD exacerbation should be treated with additional bronchodilators \pm glucocorticosteroids; ${ }^{\text {b }}$ Classes of antibiotics are provided (with specific agents in parentheses); 'No particular order. ${ }^{\mathrm{d}}$ Cardinal symptoms are increased: dyspnea, sputum volume, and sputum purulence; ${ }^{\mathrm{e}}$ This antibiotic is not appropriate in areas where there is increased prevalence of $\beta$-lactamase producing Haemophilus influenzae and Moraxella catarrhalis and/or of Streptococcus pneumoniae resistant to penicillin; ${ }^{\mathfrak{}} \mathrm{Not}$ available in all areas of the world; 'Dose $750 \mathrm{mg}$ effective against Pseudomonas aeruginosa. Reproduced with permission.' Global Initiative for Chronic Obstructive Lung Disease (GOLD). Global Strategy for the Diagnosis, Management, and Prevention of COPD [updated December 20I0]. Available from: http://www.goldcopd.org/Guidelineitem. asp? I| =2\&|2= | \&intld=989. Accessed April 13, 201 I.

Abbreviation: COPD, chronic obstructive pulmonary disease.

penetration into pulmonary airways, efficacy of microbial clearance, treatment duration, likelihood of pathogen recurrence, and any drug-related adverse events. ${ }^{39}$

Adding antibiotics to corticosteroid therapy has been shown to prolong the time to the next exacerbation and to reduce the risk of a new exacerbation versus corticosteroid use alone. ${ }^{40}$ One meta-analysis showed that treatment duration ( $\leq 5$ days) did not affect the cure rates attributed to broad-spectrum antibiotics, ${ }^{41}$ whereas another meta-analysis showed a lower risk of treatment failure for broad-spectrum versus narrow-spectrum antibiotics. ${ }^{42} \mathrm{~A}$ randomized trial of a broad spectrum antibiotic, doxycycline, added to systemic corticosteroids in selected patients hospitalized with acute exacerbations of COPD (AECOPD), demonstrated similar clinical success on day 30 in intent-to-treat (odds ratio 1.3, 95\% confidence interval [CI] 0.8-2.0) and per-protocol patients, but on day 10 those receiving doxycycline demonstrated improvement in symptom score, microbiologic outcome, and clinical cure. ${ }^{43}$ In this study, patients with higher CRP levels treated with antibiotics had a better response than those in the placebo group, suggesting a potential future importance for this biomarker in defining therapeutic paths.

\section{Oxygen and noninvasive ventilation}

Oxygen requirements typically increase during exacerbations. Oxygen supplementation and/or ventilation should be considered for patients who are experiencing signs of respiratory failure (eg, worsening hypercapnia, hypoxemia, acidosis, or pulmonary embolism) or have coexisting conditions such as myocardial infarction or sepsis. ${ }^{44}$ Long-term oxygen therapy (indicated if saturation level is below 88\%) can correct hypoxemia in patients with very severe COPD and improve overall health status. ${ }^{1}$ If the patient is discharged from the hospital on oxygen or on higher amounts of oxygen than on admission, the oxygen requirement must be reevaluated as the patient improves, in order to better define long-term requirements.

If patients with severe exacerbations are poorly responsive to oxygen supplementation alone, they may 
be candidates for ventilatory support to avoid intubation, including noninvasive ventilation (NIV) in the case of eligible individuals. ${ }^{1}$ Although the prognosis is poor for all patients requiring ventilatory support, evidence based on data from a subset of patients suggests that NIV reduces morbidity and mortality rates and intensive care unit or hospital lengths of stay. ${ }^{45}$

\section{Reduction/prevention of exacerbations}

Although patients hospitalized with severe exacerbations usually receive recommended care, most patients are not discharged with appropriate support and medications. ${ }^{19}$ It is debatable whether health care insurances will continue to pay for potentially avoidable COPD-related hospital readmissions. Thus, there is a growing impetus to prevent or reduce exacerbation severity in the primary care outpatient setting to avoid hospitalization. Patients with exacerbations may benefit from risk reduction measures and maintenance pharmacotherapies, supplemented with self-management plans, as part of pulmonary rehabilitation (PR).

\section{Risk reduction}

Results from a large-scale retrospective analysis of current and former smokers showed that smoking cessation significantly reduced exacerbations after adjusting for age, comorbidities, disease severity, and socioeconomic status (adjusted hazard ratio [HR] 0.78, 95\% CI 0.75-0.87). ${ }^{46}$ These data support guideline recommendations for smoking cessation as a risk reduction measure regardless of disease status. ${ }^{1}$

Seasonal influenza and pneumococcal pneumonia vaccinations should be standard, as appropriate for COPD patients, according to the GOLD guidelines. ${ }^{1}$ Elderly COPD patients (aged $\geq 65$ years), in particular, suffer significant adverse events from influenza and derive health benefits from vaccinations in the form of fewer hospitalizations, outpatient visits, and fatalities. Immunizations in this highrisk group should, therefore, be a priority for all clinicians. ${ }^{47}$ Consideration should also be given to providing a one-time dose of the tetanus-diphtheria-acellular-pertussis (Tdap) vaccine to previously unvaccinated individuals with COPD (aged $<65$ years), based on medical and other indications; ${ }^{48}$ for example, in the face of a pertussis epidemic in local children. The Advisory Committee on Immunization Practices recommends Tdap for older individuals (aged $\geq 65$ years) not previously immunized with this vaccine who anticipate close contact to infants (aged $<12$ months). ${ }^{48,49}$
Antibiotic prophylaxis with a low-dose macrolide has emerged as another possible therapeutic option for reducing exacerbation frequency. In a 12-month study of COPD patients experiencing moderate and/or severe exacerbations $35 \%$ experienced three or more exacerbations in the year before recruitment), twice-daily administration of erythromycin, was associated with a significant reduction in exacerbations compared with placebo. ${ }^{50}$ Results from a prospective, randomized, double-blind, placebo-controlled trial showed that long-term, once-daily administration of azithromycin, in addition to usual care, decreased the frequency of AECOPD (1.47 versus 1.84/patient-year, $P=0.004)$ and improved the quality of life of exacerbationprone COPD patients. $^{51}$

\section{Maintenance pharmacotherapies}

Results from two megatrials, Understanding Potential Longterm Impacts on Function with Tiotropium (UPLIFT $\left.{ }^{\circledR}\right)^{52}$ and Towards a Revolution in COPD Health (TORCH), ${ }^{53}$ have shown a benefit for a long-acting anticholinergic (LAAC), tiotropium, and a LABA/ICS combination (salmeterol/ fluticasone) in reducing key clinical endpoints, including exacerbations. The United States Food and Drug Administration (FDA) has approved tiotropium to reduce exacerbations in COPD patients and salmeterol/fluticasone to reduce exacerbations in COPD patients with a history of exacerbations. In the UPLIFT trial, median time to the first exacerbation was 16.7 months (95\% CI 14.9-17.9) in the tiotropium group versus 12.5 months (95\% CI 11.5-13.8) in the placebo group (HR 0.86, 95\% CI 0.81-0.91). Tiotropium treatment was also associated with a $14 \%$ decrease in the mean number of exacerbations versus placebo $(P<0.001) .^{52}$

A study by Niewoehner et al showed tiotropium reduced the proportion of patients with moderate to severe COPD experiencing exacerbations and may reduce health care utilization compared with placebo. ${ }^{54}$ In this study, the treatment groups received "usual care" as well as study treatment that could include respiratory medications other than anticholinergic bronchodilators, which may reflect "real-world" practice. ${ }^{54}$ In the 3 -year TORCH study, salmeterol/fluticasone $(50 \mu \mathrm{g} / 500 \mu \mathrm{g})$ treatment versus placebo resulted in a rate ratio for exacerbations of $0.75(95 \% \mathrm{CI}$ $0.69-0.81 ; P<0.001$ ), which is a reduction of $25 \%$ in affected individuals. ${ }^{53}$ Another 1 -year study showed that treatment with salmeterol/fluticasone $(50 \mu \mathrm{g} / 250 \mu \mathrm{g})$ reduced exacerbation rates in patients with moderate to severe COPD by $30.5 \%$ compared with salmeterol. ${ }^{55} \mathrm{~A}$ direct comparison of tiotropium $(18 \mu \mathrm{g})$ and salmeterol/fluticasone 
$(50 \mu \mathrm{g} / 500 \mu \mathrm{g})$ in patients with severe to very severe COPD showed no statistical difference in exacerbation rates over 2 years. ${ }^{56}$ However, tiotropium $(18 \mu \mathrm{g})$ was more effective than salmeterol $(50 \mu \mathrm{g})$ in all assessed exacerbation endpoints and across all the major subgroups, according to a separate 1-year comparative study of only the LAAC and LABA given to patients with moderate to severe COPD and a history of exacerbations. ${ }^{57}$

Another LABA/ICS combination, budesonide/formoterol (not FDA-indicated for COPD exacerbations), administered to patients with moderate to severe COPD, reduced systemic steroid-requiring exacerbations versus formoterol alone in a 6-month study $(20 \%-25 \%$ exacerbation reductions with budesonide-containing treatments versus formoterol or placebo alone).$^{58}$ Similarly, a 1-year study of the treatment effects of these agents showed 25\%-29\% lowered exacerbation rates (with budesonidecontaining therapies) beyond reductions achieved with formoterol alone..$^{59}$ In addition, budesonide/formoterol plus tiotropium specifically reduced the number of exacerbations by $62 \%$ versus tiotropium treatment alone. ${ }^{60}$ Roflumilast, an oral phosphodiesterase-4 inhibitor, is indicated in the United States as a treatment to reduce the risk of COPD exacerbations in patients with severe COPD associated with chronic bronchitis and a history of exacerbations (up to $18 \%$ exacerbation reduction noted in studies). ${ }^{61}$

\section{Adherence}

Adherence to disease management guidelines by clinicians and individualized patient education to optimize adherence to medications and nonpharmacological treatments may be key factors in lowering exacerbation rates. Suboptimal medication adherence, whether as a consequence of patient-specific factors (costs, physical or psychosocial factors, or insufficient education by the physician), ${ }^{62-64}$ less-than-optimal implementation of guideline-recommended therapy by physicians, ${ }^{65}$ or polypharmacy due to comorbidities, ${ }^{64}$ remains a tremendously important issue. Prescribing appropriate treatment regimens can only be effective if the patient continues to take their medication. In a survey of over a 1000 COPD patients, $50 \%$ had $6-10$ comorbidities, over $30 \%$ were receiving 5-10 non-COPD medications, and over $20 \%$ were receiving over 11 non-COPD medications. ${ }^{64}$ Inhaler misuse may also contribute to suboptimal medication adherence. ${ }^{66}$ It is important for clinicians to keep all these factors in mind, since adherence to inhaled COPD medications has been correlated with reduced hospital admissions and mortality risk due to exacerbations. ${ }^{1}$

\section{Pulmonary rehabilitation}

PR as an adjunctive therapy can improve dyspnea, exercise tolerance, and health-related quality of life, as well as reduce recurrent exacerbations and, hence, the risk of hospitalization in some patients. ${ }^{1}$ Stage-appropriate PR should include one or more aspects of disease and inhaler education, optimization of daily living activities, self-management of symptoms, anxiety and stress control, oxygen therapy, guidance for early detection and treatment of COPD exacerbations, smoking cessation, nutrition, structured exercise, and increased physical activity at home. ${ }^{67} \mathrm{~A}$ systematic review has shown that PR has the potential to reduce the number of exacerbations and associated hospital visits as well as their severity. ${ }^{68} \mathrm{In}$ a multicenter study, tiotropium plus PR-treated patients experienced fewer exacerbations and exacerbation days, and improvements in health-related quality of life, relative to the tiotropium-only group. ${ }^{69}$ Clinically meaningful changes in exercise tolerance, dyspnea, and fatigue were observed in United Kingdom patients treated for exacerbations in a hospital setting and enrolled 10 days post discharge in an 8 -week PR program (10\% of rehabilitated patients versus $42 \%$ of usual-care patients; $P=0.01$ ). Shuttle-walk distance was nearly doubled in rehabilitated patients, and dyspnea and fatigue were significantly reduced. ${ }^{70}$

Beginning PR after resolution of an acute exacerbation resulted in reduced health care utilization and costs in a separate United States study. ${ }^{71}$ Since this is, in essence, a behavioral intervention, durable health benefits can be reaped only if a patient can sustain behavior and lifestyle changes over the long term.

\section{Cardiac protective therapies}

Cardiovascular events are extremely common in COPD patients and impact morbidity and mortality. ${ }^{64,72,73}$ These diseases cause $25 \%$ of deaths and nearly $50 \%$ of hospitalizations in patients with mild to moderate COPD, as well as significantly increasing the duration of hospitalization and risk of premature death in patients with severe exacerbations. ${ }^{73,74}$ It has also been suggested that all patients who have frequent exacerbations may need treatments to reduce cardiovascular events during stable disease periods. ${ }^{75}$

European guidelines state that COPD is not a contraindication for evidence-based cardiovascular disease treatment with 
$\beta$-blockers, ${ }^{76}$ however, their underuse in COPD has classically been associated with concern over the risk of worsening bronchospasm. Emerging evidence suggests that treatment with cardioselective $\beta$-blockers is safe, well tolerated, and reduces the risk of exacerbations and premature deaths in COPD patients with coexisting cardiovascular disease. ${ }^{77,78} \mathrm{In}$ the absence of larger prospective randomized clinical trials, the decision to use $\beta$-blockers in COPD patients must be made very carefully. However, the concept that bronchodilators (eg, $\beta$-agonists) and $\beta$-blockers could both decrease exacerbations further emphasizes the complexity of these events.

\section{Self-management}

Self-management plans empower patients with a history of exacerbations by teaching problem-solving skills, including recognition and interpretation of symptom changes, and next steps (eg, seeking access to appropriate care). Patient education is a vital aspect of guided self-management in order to address some of the issues underlying suboptimal medication adherence, such as compromised inhaler technique (as described in detail elsewhere). ${ }^{66}$

Written action plans are also important components of self-management and could be part of PR or an existing chronic care program. One example currently being evaluated by the Canadian Thoracic Society ${ }^{79}$ provides patients with advice on self- or medical-care visits, as appropriate. Analyses of the benefits of action plans have produced variable results, mainly because of the heterogeneity in plans, study populations, follow-up time, and outcome measures, ${ }^{80}$ although two separate analyses showed that self-management plans increased appropriate treatment ${ }^{81}$ and reduced exacerbation recovery time. ${ }^{82}$ Where feasible, a 24-hour telephone support service may reduce the number of hospitalizations. ${ }^{83}$ Other forms of support can be considered to supplement selfmanagement plans (eg, Web-based consultation services or videophones); however, this type of home monitoring may be expensive to set up, and many older patients may not be able to master the technology. While self-management plans are very important, their benefits have yet to be evaluated in patients immediately following hospitalization or in those who are prone to frequent exacerbations.

\section{Lung volume reduction surgery}

Lung volume reduction surgery has been shown to improve the quality of life, exercise capacity, and survival in a carefully selected group of patients with upper-lobe predominant emphysema ${ }^{84}$ The evidence suggests that patients who meet pre-specified criteria for surgery and undergo the procedure may receive an additional benefit in terms of a reduction in exacerbations, potentially by improving respiratory mechanics and decreasing the volume of trapped air from hyperinflated regions of the lungs. ${ }^{85}$

\section{Summary}

Many patients with COPD delay reporting exacerbations, which leads to detrimental consequences to their quality of life. ${ }^{29}$ Severe exacerbations, usually involving hospitalization, are associated with enormous health and socioeconomic costs. Short-acting bronchodilators and oxygen are prescribed to relieve dyspnea, corticosteroids to decrease inflammation during an acute exacerbation, and appropriate antibiotic therapy to treat bacterial infections. A long-term treatment plan should include one or more available classes of drugs (LAAC, LABA [alone or in combination], an ICS/ LABA combination, and phosphodiesterase- 4 inhibitor) that represent maintenance pharmacotherapies to prevent future exacerbations, as well as management of coexisting nonpulmonary conditions and strategies to optimize adherence to inhaled medications. Supplementary PR may be important in preventing or delaying the recurrence of exacerbations in some patients after they have recovered from an acute event. Self-management plans, as part of PR or a chronic care program, may contribute to a reduction in the frequency and severity of exacerbations.

\section{Conclusion}

Exacerbations affect patient longevity and quality of life, thereby dramatically contributing to the cost of care for affected individuals. By helping to prevent, recognize, and appropriately treat these events, clinicians can have a major impact on the course of COPD.

\section{Acknowledgments}

Manuscript preparation, including medical writing assistance, which was provided by Zeena Nackerdien, PhD, of Envision Scientific Solutions, was supported by Boehringer Ingelheim Pharmaceuticals, Inc and Pfizer Inc. The article reflects the concepts of the authors and is their sole responsibility. It was not reviewed by Boehringer Ingelheim Pharmaceuticals, Inc and Pfizer Inc, except to ensure medical and safety accuracy.

\section{Disclosure}

Dr Yawn participated in COPD studies from Boehringer Ingelheim, Novartis, and GlaxoSmithKline, for which 
Olmsted Medical Center received funding, and served on an advisory meeting for Novartis, with honoraria paid to Olmsted Medical Center. Dr Thomashow has been a member of advisory boards for Boehringer Ingelheim, GlaxoSmithKline, Intermune, Forrest Pharmaceuticals, and Talecris.

\section{References}

1. Global Initiative for Chronic Obstructive Lung Disease (GOLD). Global Strategy for the Diagnosis, Management, and Prevention of COPD [updated December 2010]. Available from: http:/www.goldcopd.org/uploads/users/ files/GOLDReport_April112011.pdf. Accessed April 13, 2011.

2. World Health Organization. Chronic obstructive pulmonary disease. Fact sheet No. 315. Available from: http:/www.goldcopd.org/guidelines-globalstrategy-for-diagnosis-management.html. Accessed August 26, 2011.

3. Toy EL, Gallagher KF, Stanley EL, Swensen AR, Duh MS. The economic impact of exacerbations of chronic obstructive pulmonary disease and exacerbation definition: a review. COPD. 2010;7(3): 214-228.

4. Mannino DM, Buist AS. Global burden of COPD: risk factors, prevalence, and future trends. Lancet. 2007;370(9589):765-773.

5. Bourbeau J, Ford G, Zackon H, Pinsky N, Lee J, Ruberto G. Impact on patients' health status following early identification of a COPD exacerbation. Eur Respir J. 2007;30(5):907-913.

6. Donaldson GC, Wedzicha JA. COPD exacerbations.1: Epidemiology. Thorax. 2006;61(2):164-168.

7. O'Reilly JF, Williams AE, Holt K, Rice L. Defining COPD exacerbations: impact on estimation of incidence and burden in primary care. Prim Care Respir J. 2006;15(6):346-353.

8. Soler-Cataluna JJ, Martinez-Garcia MA, Roman Sanchez P, Salcedo E, Navarro M, Ochando R. Severe acute exacerbations and mortality in patients with chronic obstructive pulmonary disease. Thorax. 2005;60(11):925-931.

9. Hurst JR, Vestbo J, Anzueto A, et al. Susceptibility to exacerbation in chronic obstructive pulmonary disease. N Engl J Med. 2010;363(12): 1128-1138.

10. Seemungal TA, Donaldson GC, Bhowmik A, Jeffries DJ, Wedzicha JA. Time course and recovery of exacerbations in patients with chronic obstructive pulmonary disease. Am J Respir Crit Care Med. 2000; 161(5):1608-1613.

11. Stevenson NJ, Walker PP, Costello RW, Calverley PM. Lung mechanics and dyspnea during exacerbations of chronic obstructive pulmonary disease. Am J Respir Crit Care Med. 2005;172(12): 1510-1516.

12. Hurst JR, Donaldson GC, Quint JK, Goldring JJ, Baghai-Ravary R, Wedzicha JA. Temporal clustering of exacerbations in chronic obstructive pulmonary disease. Am J Respir Crit Care Med. 2009;179(5): 369-374.

13. Adams SG, Melo J, Luther M, Anzueto A. Antibiotics are associated with lower relapse rates in outpatients with acute exacerbations of COPD. Chest. 2000;117(5):1345-1352.

14. McGhan R, Radcliff T, Fish R, Sutherland ER, Welsh C, Make B. Predictors of rehospitalization and death after a severe exacerbation of COPD. Chest. 2007;132(6):1748-1755.

15. Murata GH, Gorby MS, Chick TW, Halperin AK. Treatment of decompensated chronic obstructive pulmonary disease in the emergency department - correlation between clinical features and prognosis. Ann Emerg Med. 1991;20(2):125-129.

16. Patil SP, Krishnan JA, Lechtzin N, Diette GB. In-hospital mortality following acute exacerbations of chronic obstructive pulmonary disease. Arch Intern Med. 2003;163(10):1180-1186.

17. Ai-Ping C, Lee KH, Lim TK. In-hospital and 5-year mortality of patients treated in the ICU for acute exacerbation of COPD: a retrospective study. Chest. 2005;128(2):518-524.
18. Lindenauer PK, Pekow P, Gao S, Crawford AS, Gutierrez B, Benjamin EM. Quality of care for patients hospitalized for acute exacerbations of chronic obstructive pulmonary disease. Ann Intern Med. 2006;144(12):894-903.

19. Yip NH, Yuen G, Lazar EJ, et al. Analysis of hospitalizations for COPD exacerbation: opportunities for improving care. COPD. 2010;7(2): $85-92$.

20. Wedzicha JA, Seemungal TA. COPD exacerbations: defining their cause and prevention. Lancet. 2007;370(9589):786-796.

21. Murphy TF, Brauer AL, Eschberger K, et al. Pseudomonas aeruginosa in chronic obstructive pulmonary disease. Am J Respir Crit Care Med. 2008;177(8):853-860.

22. Bonhoeffer J, Bar G, Riffelmann M, Soler M, Heininger U. The role of Bordetella infections in patients with acute exacerbation of chronic bronchitis. Infection. 2005;33(1):13-17.

23. Schneider D, Ganesan S, Comstock AT, et al. Increased cytokine response of rhinovirus-infected airway epithelial cells in chronic obstructive pulmonary disease. Am J Respir Crit Care Med. 2010; 182(3):332-340.

24. Donaldson GC, Hurst JR, Smith CJ, Hubbard RB, Wedzicha JA. Increased risk of myocardial infarction and stroke following exacerbation of COPD. Chest. 2010;137(5):1091-1097.

25. Bhowmik A, Seemungal TA, Sapsford RJ, Wedzicha JA. Relation of sputum inflammatory markers to symptoms and lung function changes in COPD exacerbations. Thorax. 2000;55(2):114-120.

26. Donaldson GC, Seemungal TA, Patel IS, et al. Airway and systemic inflammation and decline in lung function in patients with COPD. Chest. 2005;128(4):1995-2004.

27. Spruit MA, Gosselink R, Troosters T, et al. Muscle force during an acute exacerbation in hospitalised patients with COPD and its relationship with CXCL8 and IGF-I. Thorax. 2003;58(9):752-756.

28. Holguin F, Folch E, Redd SC, Mannino DM. Comorbidity and mortality in COPD-related hospitalizations in the United States, 1979 to 2001. Chest. 2005;128(4):2005-2011.

29. Langsetmo L, Platt RW, Ernst P, Bourbeau J. Underreporting exacerbation of chronic obstructive pulmonary disease in a longitudinal cohort. Am J Respir Crit Care Med. 2008;177(4):396-401.

30. Marin JM, Carrizo SJ, Casanova C, et al. Prediction of risk of COPD exacerbations by the BODE index. Respir Med. 2009;103(3): 373-378.

31. Jones RC, Donaldson GC, Chavannes NH, et al. Derivation and validation of a composite index of severity in chronic obstructive pulmonary disease: the DOSE Index. Am J Respir Crit Care Med. 2009;180(12): 1189-1195.

32. Leidy NK, Wilcox TK, Jones PW, Roberts L, Powers JH, Sethi S. Standardizing measurement of chronic obstructive pulmonary disease exacerbations: reliability and validity of a patient-reported diary. $\mathrm{Am}$ J Respir Crit Care Med. 2011;183(3):323-329.

33. Stolz D, Christ-Crain M, Bingisser R, et al. Antibiotic treatment of exacerbations of COPD: a randomized, controlled trial comparing procalcitonin-guidance with standard therapy. Chest. 2007;131(1): 9-19.

34. Lacoma A, Prat C, Andreo F, et al. Value of procalcitonin, C-reactive protein, and neopterin in exacerbations of chronic obstructive pulmonary disease. Int J Chron Obstruct Pulmon Dis. 2011;6: 157-169.

35. Bazeghi N, Gerds TA, Budtz-Jorgensen E, Hove J, Vestbo J. Exhaled nitric oxide measure using multiple flows in clinically relevant subgroups of COPD. Respir Med. 2011;105(9): 1338-1344.

36. Anthonisen NR, Manfreda J, Warren CP, Hershfield ES, Harding GK, Nelson NA. Antibiotic therapy in exacerbations of chronic obstructive pulmonary disease. Ann Intern Med. 1987;106(2): 196-204.

37. Celli BR, MacNee W. Standards for the diagnosis and treatment of patients with COPD: a summary of the ATS/ERS position paper. Eur Respir J. 2004;23(6):932-946. 
38. Kesten S, Celli B, Decramer M, Leimer I, Tashkin D. Tiotropium HandiHaler in the treatment of COPD: a safety review. Int J Chron Obstruct Pulmon Dis. 2009;4:397-409.

39. Sethi S, Murphy TF. Infection in the pathogenesis and course of chronic obstructive pulmonary disease. N Engl J Med. 2008;359(22): 2355-2365.

40. Roede BM, Bresser P, Bindels PJ, et al. Antibiotic treatment is associated with reduced risk of a subsequent exacerbation in obstructive lung disease: an historical population based cohort study. Thorax. 2008; 63(11):968-973.

41. El Moussaoui R, Roede BM, Speelman P, Bresser P, Prins JM, Bossuyt PM. Short-course antibiotic treatment in acute exacerbations of chronic bronchitis and COPD: a meta-analysis of double-blind studies. Thorax. 2008;63(5):415-422.

42. Dimopoulos G, Siempos II, Korbila IP, Manta KG, Falagas ME. Comparison of first-line with second-line antibiotics for acute exacerbations of chronic bronchitis: a metaanalysis of randomized controlled trials. Chest. 2007;132(2):447-455.

43. Daniels JM, Snijders D, de Graaff CS, Vlaspolder F, Jansen HM, Boersma WG. Antibiotics in addition to systemic corticosteroids for acute exacerbations of chronic obstructive pulmonary disease. Am J Respir Crit Care Med. 2010;181(2):150-157.

44. Rabe KF, Hurd S, Anzueto A, et al. Global strategy for the diagnosis, management, and prevention of chronic obstructive pulmonary disease: GOLD executive summary. Am J Respir Crit Care Med. 2007;176(6): 532-555.

45. Mehta S, Hill NS. Noninvasive ventilation. Am J Respir Crit Care Med. 2001;163(2):540-577.

46. Au DH, Bryson CL, Chien JW, et al. The effects of smoking cessation on the risk of chronic obstructive pulmonary disease exacerbations. J Gen Intern Med. 2009;24(4):457-463.

47. Nichol KL, Baken L, Nelson A. Relation between influenza vaccination and outpatient visits, hospitalization, and mortality in elderly persons with chronic lung disease. Ann Intern Med. 1999;130(5):397-403.

48. Advisory Committee on Immunization Practices. Recommended adult immunization schedule: United States, 2011. Ann Intern Med. 2011; 154(3):168-173.

49. Kretsinger K, Broder KR, Cortese MM, et al. Preventing tetanus, diphtheria, and pertussis among adults: use of tetanus toxoid, reduced diphtheria toxoid and acellular pertussis vaccine recommendations of the Advisory Committee on Immunization Practices (ACIP) and recommendation of ACIP, supported by the Healthcare Infection Control Practices Advisory Committee (HICPAC), for use of Tdap among health-care personnel. MMWR Recomm Rep. 2006;55(RR-17): $1-37$.

50. Seemungal TA, Wilkinson TM, Hurst JR, Perera WR, Sapsford RJ, Wedzicha JA. Long-term erythromycin therapy is associated with decreased chronic obstructive pulmonary disease exacerbations. Am J Respir Crit Care Med. 2008;178(11):1139-1147.

51. Albert RK, Bailey WC, Casaburi R, et al. Chronic azithromycin decreases the frequency of chronic obstructive pulmonary disease exacerbations. Am J Respir Crit Care Med. 2011;183:A6416.

52. Tashkin DP, Celli B, Senn S, et al. A 4-year trial of tiotropium in chronic obstructive pulmonary disease. N Engl J Med. 2008;359(15): 1543-1554.

53. Calverley PM, Anderson JA, Celli B, et al. Salmeterol and fluticasone propionate and survival in chronic obstructive pulmonary disease. N Engl J Med. 2007;356(8):775-789.

54. Niewoehner DE, Rice K, Cote C, et al. Prevention of exacerbations of chronic obstructive pulmonary disease with tiotropium, a once-daily inhaled anticholinergic bronchodilator: a randomized trial. Ann Intern Med. 2005;143(5):317-326.

55. Ferguson GT, Anzueto A, Fei R, Emmett A, Knobil K, Kalberg C. Effect of fluticasone propionate/salmeterol (250/50 microg) or salmeterol (50 microg) on COPD exacerbations. Respir Med. 2008; 102(8):1099-1108.
56. Wedzicha JA, Calverley PM, Seemungal TA, Hagan G, Ansari Z, Stockley RA. The prevention of chronic obstructive pulmonary disease exacerbations by salmeterol/fluticasone propionate or tiotropium bromide. Am J Respir Crit Care Med. 2008;177(1):19-26.

57. Vogelmeier C, Hederer B, Glaab T, et al. Tiotropium versus salmeterol for the prevention of exacerbations of COPD. $N$ Engl J Med. 2011; 364(12):1093-1103.

58. Tashkin DP, Rennard SI, Martin P, et al. Efficacy and safety of budesonide and formoterol in one pressurized metered-dose inhaler in patients with moderate to very severe chronic obstructive pulmonary disease: results of a 6-month randomized clinical trial. Drugs. 2008;68(14): 1975-2000.

59. Rennard SI, Tashkin DP, McElhattan J, et al. Efficacy and tolerability of budesonide/formoterol in one hydrofluoroalkane pressurized metereddose inhaler in patients with chronic obstructive pulmonary disease: results from a 1-year randomized controlled clinical trial. Drugs. 2009; 69(5):549-565.

60. Welte T, Miravitlles M, Hernandez P, et al. Efficacy and tolerability of budesonide/formoterol added to tiotropium in patients with chronic obstructive pulmonary disease. Am J Respir Crit Care Med. 2009; 180(8):741-750.

61. Prescribing information for Daliresp ${ }^{\text {TM }}$ (roflumilast) tablets: initial US approval. 2011. Available from: http://www.frx.com/pi/Daliresp_pi.pdf. Accessed March 7, 2011.

62. Bourbeau J, Bartlett SJ. Patient adherence in COPD. Thorax. 2008;63(9):831-838.

63. Restrepo RD, Alvarez MT, Wittnebel LD, et al. Medication adherence issues in patients treated for COPD. Int J Chron Obstruct Pulmon Dis. 2008;3(3):371-384.

64. Barr RG, Celli BR, Mannino DM, et al. Comorbidities, patient knowledge, and disease management in a national sample of patients with COPD. Am J Med. 2009;122(4):348-355.

65. Sarc I, Jeric T, Ziherl K, et al. Adherence to treatment guidelines and long-term survival in hospitalized patients with chronic obstructive pulmonary disease. J Eval Clin Pract. Epub 2011 Jan 11.

66. Fink J, Hodder R. Adherence and inhaler devices in COPD. Respir Ther. 2011;6:28-33.

67. Riario-Sforza GG, Yacoub MR, Incorvaia C. Pulmonary rehabilitation as evaluated by clinical trials: an overview. Rev Recent Clin Trials. 2010;5(2):76-84.

68. Puhan MA, Scharplatz M, Troosters T, Steurer J. Respiratory rehabilitation after acute exacerbation of COPD may reduce risk for readmission and mortality - a systematic review. Respir Res. 2005;6:54.

69. Ambrosino N, Foglio K, Balzano G, Paggiaro PL, Lessi P, Kesten S. Tiotropium and exercise training in COPD patients: effects on dyspnea and exercise tolerance. Int J Chron Obstruct Pulmon Dis. 2008;3(4): 771-780.

70. Man WD, Polkey MI, Donaldson N, Gray BJ, Moxham J. Community pulmonary rehabilitation after hospitalisation for acute exacerbations of chronic obstructive pulmonary disease: randomised controlled study. BMJ. 2004;329(7476):1209.

71. Raskin J, Spiegler P, McCusker C, et al. The effect of pulmonary rehabilitation on healthcare utilization in chronic obstructive pulmonary disease: The Northeast Pulmonary Rehabilitation Consortium. J Cardiopulm Rehabil. 2006;26(4):231-236.

72. Chatila WM, Thomashow BM, Minai OA, Criner GJ, Make BJ. Comorbidities in chronic obstructive pulmonary disease. Proc Am Thorac Soc. 2008;5(4):549-555.

73. Kinnunen T, Saynajakangas O, Tuuponen T, Keistinen T. Impact of comorbidities on the duration of COPD patients' hospital episodes. Respir Med. 2003;97(2):143-146.

74. Anthonisen NR, Connett JE, Enright PL, Manfreda J. Hospitalizations and mortality in the Lung Health Study. Am J Respir Crit Care Med. 2002;166(3):333-339.

75. Calverley PM, Sanchez-Toril F, McIvor A, Teichmann P, Bredenbroeker D, Fabbri LM. Effect of 1-year treatment with roflumilast in severe chronic obstructive pulmonary disease. Am J Respir Crit Care Med. 2007;176(2):154-161. 
76. Dickstein K, Cohen-Solal A, Filippatos G, et al. ESC guidelines for the diagnosis and treatment of acute and chronic heart failure 2008: the task force for the diagnosis and treatment of acute and chronic heart failure 2008 of the European Society of Cardiology. Developed in collaboration with the Heart Failure Association of the ESC (HFA) and endorsed by the European Society of Intensive Care Medicine (ESICM). Eur J Heart Fail. 2008;10(10):933-989.

77. van Gestel YR, Hoeks SE, Sin DD, et al. Impact of cardioselective betablockers on mortality in patients with chronic obstructive pulmonary disease and atherosclerosis. Am J Respir Crit Care Med. 2008;178(7): 695-700.

78. Rutten FH, Zuithoff NP, Hak E, Grobbee DE, Hoes AW. Beta-blockers may reduce mortality and risk of exacerbations in patients with chronic obstructive pulmonary disease. Arch Intern Med. 2010;170(10): 880-887.

79. Canadian Thoracic Society. COPD action plan. 2008 [updated 2008 Oct 20]. Available from: http://www.lung.ca/pdf/1408_THOR_Action Plan_v3.pdf. Accessed August 26, 2011.

80. Effing T, Monninkhof EM, van der Valk PD, et al. Self-management education for patients with chronic obstructive pulmonary disease. Cochrane Database Syst Rev. 2007;4:CD002990.
81. Wood-Baker R, McGlone S, Venn A, Walters EH. Written action plans in chronic obstructive pulmonary disease increase appropriate treatment for acute exacerbations. Respirology. 2006;11(5):619-626.

82. Sedeno MF, Nault D, Hamd DH, Bourbeau J. A self-management education program including an action plan for acute COPD exacerbations. COPD. 2009;6(5):352-358.

83. Hurst JR, Fitzgerald-Khan F, Quint JK, et al. Use and utility of a 24-hour telephone support service for 'high risk' patients with COPD. Prim Care Respir J. 2010;19(3):260-265.

84. Naunheim KS, Wood DE, Mohsenifar Z, et al. Long-term follow-up of patients receiving lung-volume-reduction surgery versus medical therapy for severe emphysema by the National Emphysema Treatment Trial Research Group. Ann Thorac Surg. 2006;82(2):431-443.

85. Washko GR, Fan VS, Ramsey SD, et al. The effect of lung volume reduction surgery on chronic obstructive pulmonary disease exacerbations. Am J Respir Crit Care Med. 2008;177(2):164-169.
International Journal of General Medicine

\section{Publish your work in this journal}

The International Journal of General Medicine is an international, peer-reviewed open-access journal that focuses on general and internal medicine, pathogenesis, epidemiology, diagnosis, monitoring and treatment protocols. The journal is characterized by the rapid reporting of reviews, original research and clinical studies across all disease areas.

\section{Dovepress}

A key focus is the elucidation of disease processes and management protocols resulting in improved outcomes for the patient.The manuscript management system is completely online and includes a very quick and fair peer-review system. Visit http://www.dovepress.com/ testimonials.php to read real quotes from published authors. 